Case Report

\title{
An unusual combination of primordial dwarfism with isolated cleft palate Kumar $N^{1}$, Manikandhan $R^{2}$, Anantanarayanan $P^{3}$, Agarwal $K^{4}$
}

\begin{tabular}{|}
${ }^{1}$ Dr. Nishant Kumar, MDS \\
Former Post Graduate student \\
${ }^{2}$ Dr. R. Manikandhan, MDS, FDSRCS, \\
FFDRCS \\
Professor and Director, Cleft and \\
Craniofacial Unit \\
${ }^{3}$ Dr. P. Anantanarayanan, MDS, \\
DNB, MNAMS \\
Professor \\
${ }^{4}$ Dr. Kriti Agarwal, MDS \\
Periodontist \\
$1,2,3,4$ Department of Oral and \\
Maxillofacial Surgery, \\
Meenakshi Ammal Dental College \\
and Hospital, \\
Chennai, Tamil Nadu, India \\
Received: 20-05-2012 \\
Revised: $30-05-2012$ \\
Accepted: 20-06-2012 \\
Dr. Nishant Kumar \\
drnishantmaxfac@gmail. \\
com \\
Correspondence to:
\end{tabular}

\begin{abstract}
Primordial dwarfism is a rare anomaly with over 200 sub-types, which results in a relatively small body size in all stages of life, beginning at the intrauterine period. The life expectancy for these patients is around 30 years but very few survive their intra-uterine phase. Other features associated with primary dwarfism reported till date includes pigmentation of skin, cleft lip and palate, and semilobar holoprosencephaly. We report an unusual combination of primordial dwarfism associated with isolated cleft palate.

Key Words: Primordial dwarfism, cleft palate, dwarfism with cleft palate
\end{abstract}

the diagnosis can only be made after birth by evaluating clinically their stunted growth rate, leaving primordial dwarfs perpetually years behind their peers in stature and in weight. Out of 200 types of primordial dwarfism, 5 sub types are more severe and it is estimated that there are only 100 
individuals in the world afflicted with the disorder. The life expectancy for these patients is around 30 years but very few survive their intra-uterine phase.

\section{Case Report}

A 22 year old boy reported to our cleft centre with a chief complaint of hole in the palate. His parents revealed history of consanguineous marriage. He was born at term with uneventful gestation period and birth weight of $1.5 \mathrm{Kg}$.

Clinically, the boy had a playful friendly nature that spoke few words and obeyed simple commands. His skin was dry, scaly and without hairs. His face was 'Bird like', triangular in shape with multiple scars and cornel haziness was noticed bilaterally (Fig. 1).

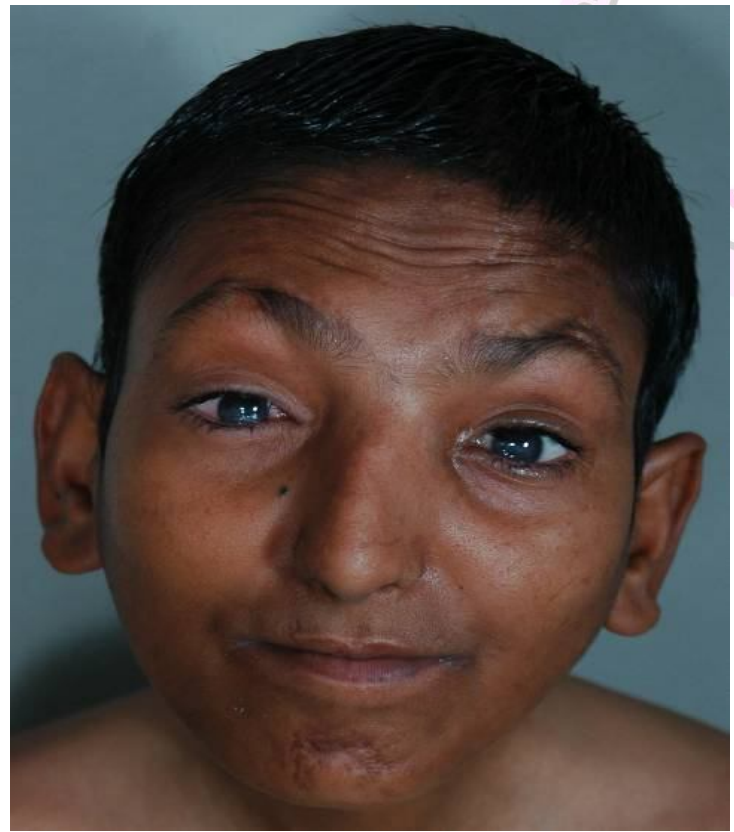

Fig.1 Bird like face with corneal haziness with abnormal lengthening of both the arms (Fig. 2).

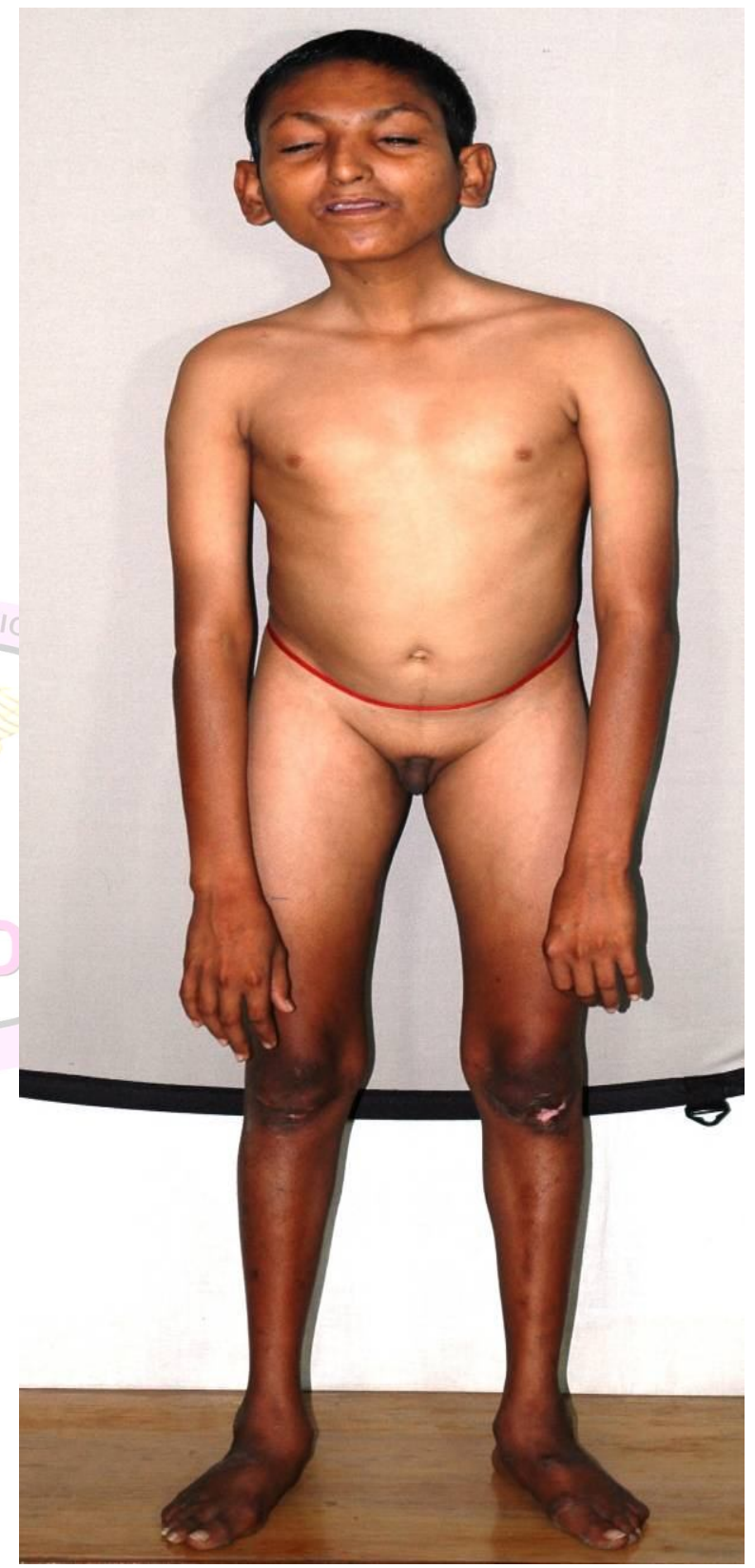

Fig.2 Physical appearance
He looked old with a 'Beak like' nose and receding chin. He had an unsteady and abnormal gait due to mild bowing of his legs
Intra oral examination revealed incomplete cleft palate with normal dentition (Fig. 3). 


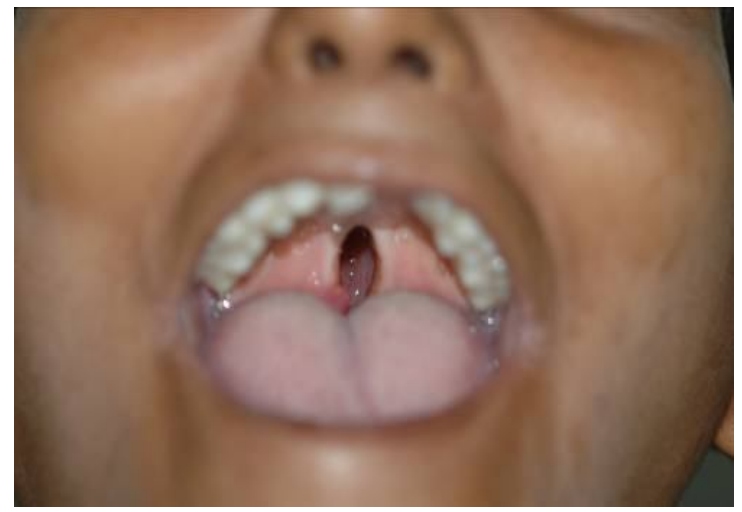

Fig.3 Incomplete Cleft Palate with normal dentition

Bilateral Hallux valgus was noticed with shortened great toe (Fig.4).

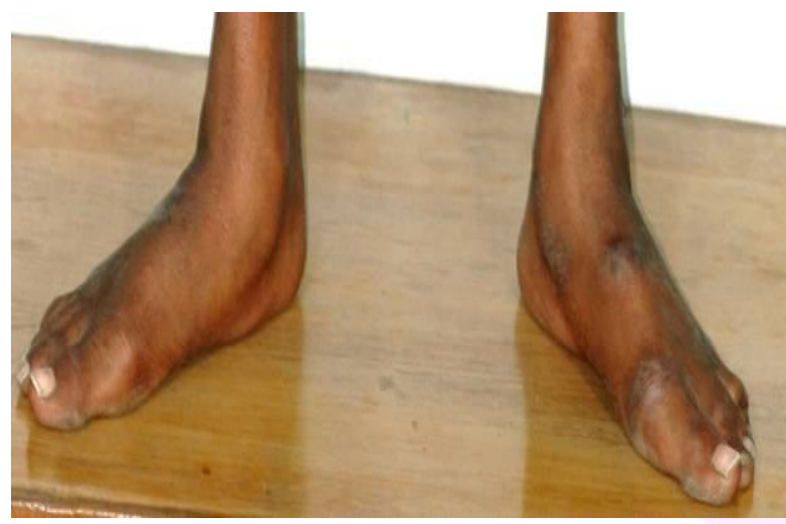

Fig.4 Bilateral Hallux Valgus

On general examination, he was short for his age. The height, weight, and occipitofrontal circumference were $130 \mathrm{~cm}(<3 \mathrm{rd}$ centile), $24.7 \mathrm{Kg}$ ( $<3 \mathrm{rd}$ centile), and $47.5 \mathrm{~cm}$ (<3rd centile) as compared with normal a range of 175 to $180 \mathrm{~cm}, 68$ to $72 \mathrm{~kg}$ and 65 to $70 \mathrm{~cm}$ respectively for his age. He showed signs of global developmental delay with delayed bone age $(>7<8$ years) and generalized decreased muscle tone. The external genitals were present but underdeveloped with absence of secondary sexual characters. CT scan of brain showed no intracranial abnormality and neurological examination was normal.
Blood investigations, thyroid function test, ultrasound of abdomen, electrocardiogram and echocardiogram were normal.

\section{Discussion}

Caroline Crachami was the first recognized individual in 1815 with primordial dwarfism. [2] The five main sub-types of primordial dwarfism are Seckel Syndrome, Osteodysplastic Primordial Dwarfism Type I, Osteodysplastic Primordial Dwarfism Type II, Russel-Silver Syndrome and Meier-Gorlin Syndrome. Other osteodysplastic cases with short stature, microdontia, opalescent teeth, and rootless molars have also been described. ${ }^{[3,4]}$

Association of seckel syndrome with cleft lip and palate present together has been documented [5] but as per our knowledge this is the first report of a combination of primordial dwarfism with isolated cleft palate. The features suggestive of primordial dwarfism in our case were primordial short stature, with height, weight, and occipito-frontal circumference less than 3 rd centile and no mental/cranial nerve dysfunction.

In view of the large number of abnormalities reported, these patients need to be evaluated thoroughly to rule out systemic problems, particularly pituitary, thyroid, and adrenal dysfunction. Seckel and Russell-Silver syndromes are the most clearly defined syndromes within the category of primordial dwarfism while accurate diagnosis is more difficult with the osteodysplastic types of primordial dwarfism, even with the most experienced geneticists. The clinical features present in our case and as described in the literature, resembled osteodysplastic primordial dwarfism type I with associated unique features like skeletal changes in the legs, abnormal hair pattern and cleft palate. 


\section{Acknowledgment}

The authors thank Dr. R. Srilakshmi, Geneticist, Dr. M.G.R. Hospital, Chennai, for the unconditional support in genetic counseling of the patient.

\section{References}

1. Hall JG, Flora C, Scott C I Jr. Osteodysplastic Primordial Dwarfism Type II (MOPD II): Natural History and Clinical Findings. Am J Med Genet. 2004; 130A:55-72.

2. Berkovitz BKB, Grigson C, Dean NC. Caroline Crachami, the Sicilian dwarf (1815-1824): Was she really nine years old at death? Am. J. Med Genet. 1998; 76:343-8.

3. Kantaputra PN. Apparently New Osteodysplastic and Primordial Short Stature with Severe Microdontia, Opalescent Teeth, and Rootless Molars in Two Siblings. Am J Med Genet. 2002; 111:420-8.

4. Majewski F, GoeckeT. Studies of microcephalic primordial dwarfism I: approach to a delineation of the Seckel syndrome. Am J Med Genet. 1982; 12:7-21.

5. Murthy J, Seshadri KG, Venkat Ramanan P. A case of cleft lip and palate associated with seckel syndrome. Cleft Palate Craniofacial Journal. 2004; 41:202-5.

Cite this article as: Kumar N,
Manikandhan R, Anantanarayanan P,
Agarwal K. An unusual combination of
primordial dwarfism with isolated cleft
palate. Int J Med and Dent Sci 2012;
$\begin{aligned} & \text { 1(2):20-23. } \\ & \text { Source of Support: Nil } \\ & \text { Conflict of Interest: No }\end{aligned}$

